\title{
THE APPLICATION OF INVERTER-DRIVEN TECHNOLOGY ON THE CRIMPING MACHINE
}

\author{
Runqing $\mathrm{Zhu}^{1}$, Lixin $\mathrm{Lu}^{2}$, Limin $\mathrm{Li}^{1}$, Huan You ${ }^{1}$ \\ ${ }^{I}$ CIMS \& Robot Center, Shanghai University, Shanghai, 200072, China; \\ Email:wykyvn@163.com. ${ }^{2}$ Shanghai Feilo Co.,LTD, Shanghai, 200050, China.
}

\begin{abstract}
In this paper, an innovative design of crimping machine which is based on inverter-driven technology and adopted embedded PSOC system hardware platform is discussed. This improvement will abandon original disadvantages such as: bulky mechanical structure , low efficient , unsteady crimping quality , heavy noise etc, and make the inverter-driven technology available to control crimping machine.
\end{abstract}

Key words: Inverter-driven, Adjustable-speed Motor, Crimping Machine, Controller.

\section{INTRODUCTION}

With the fast development of electronic products and new emerging application industry, the requirement of wire harness is increasing dramatically. Therefore, the developing prospect of the wiring harness terminal processing machine-crimping machine is expansive and optimistical. Since 1980s, the action of crimping is driven by mechanical device. Its basic structure is as follows: driven mechanism, clutch and brake mechanism and crimping mechanism, which can be seen in Figure 1.

As shown in figure 1, the energy is stored by wheel which is driven by motor, and then crimping will be carried out by slide block which is driven by clutch mechanism, after that the equipment will be stopped by brake mechanism system. Because of the complex and heavy structure as well as unstable quality and heavy noise, etc, a new prototype will be brought up with the updated control method of inverter-driven technology rather than

Please use the following format when citing this chapter:

Zhu, Runqing, Lu, Lixin, Li, Limin, You, Huan, 2006, in International Federation For Information Processing (IFIP), Volume 207, Knowledge Enterprise: Intelligent Strategies In Product Design, Manufacturing, and Management, eds. K. Wang, Kovacs G., Wozny M., Fang M., (Boston: Springer), pp. 250-256. 
bulky mechanical structure, which can abandon the original mechanical clutch and brake mechanism. This innovative design not only makes the overall equipment smooth in action, conservational in energy, high in efficiency as well as lets the machine compact in design, solid in structure and easy in maintenance.

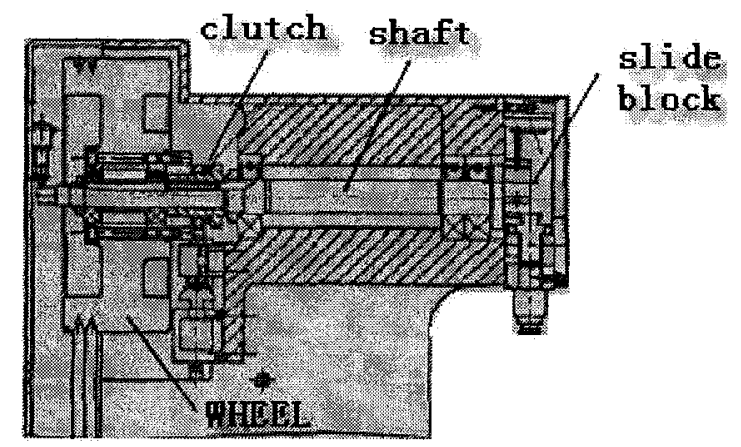

Figure 1. Mechanical structure of the crimping machine.

\section{THE THEORY OF INVERTER-DRIVEN ADJUSTABLE-SPEED SYSTEM}

Because the inverter directly drives the three-phase alternating current induction motor to drive the crimping machine, to study the theory, firstly we list the following formula that denotes the speed of the motor:

$$
n=n_{I}(1-s)=60 f_{1} / p(1-s)
$$

Where " $\mathrm{n}$ " is the speed of motor rotor;

" $\mathrm{f}_{1}$ " is source frequency of the motor stator;

" $p$ " is the number of magnetic pole pairs;

" $n_{1}$ " is synchronous speed;

"s" is the slip;

The formula shows there are three methods to adjust the speed of induction motor.

1. Change the number of magnetic pole pairs;

2. Change the source frequency;

3. Change the slip; 
The induction motor will run with a proportional and unsteady speed when changing the number of magnetic pole pairs; and have a low efficiency, unreliable mechanical characteristics when changing the source frequency; while if the slip is adjusted properly, the induction motor will has a wide speed range、 high efficiency, and could adjust for the desired speed with constant torque or constant power inverter-driven mode. With the development of Power Electronics Technology, inverter-driven adjustablespeed system is becoming the utmost important part in alternating current governor System.[1]But the source frequency will influence the other parameters of induction motor simultaneously, such as air-gap flux $\Phi_{\mathrm{m}}$ > field current , power factor 、 magnetic torque, overload ability etc. So other factors must be considered to make full use of the induction motor.

Still we have formula as follows:

$$
\mathrm{U}_{1} \approx \mathrm{E}_{1}=4.44 \mathrm{f}_{1} \mathrm{~N}_{1} \mathrm{~K}_{\mathrm{W} 1} \phi \mathrm{m}
$$

Where "U1" is the phase voltage of the motor stator;

" $E_{\mathrm{I}}$ " is phase electromotive force;

" $\mathrm{N}_{1}$ " is the total number of the motor stator winding turns;

" $\mathrm{K}_{\mathrm{WI}}$ " is the fundamental turns coefficient;

" $\phi_{\mathrm{m}}$ " is the air-gap flux;

According to formula (1) and (2), the speed of alternating current induction motor will lower when reducing the source frequency, meanwhile in order to keep the phase voltage constant, air-gap flux must increase which will lead to some disadvantage such as: magnetic circuit saturation, lower power factor、core loss etc.[2]So the phase voltage and source frequency of the motor stator must reduce simultaneously, i.e. $U_{1} / f_{1}=$ constant. And the mechanical characteristics of the induction motor can demonstrate as follows. The figure shows that it has mechanical characteristics in accord with the constant torque control mode.

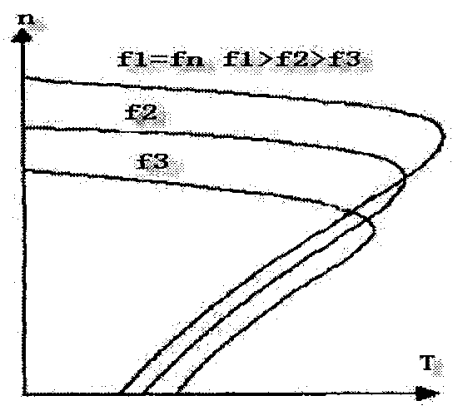

Figure 2. Constant torque mechanical characteristics. 

Machine

If the source frequency is increased, the air-gap flux must reduce to keep the phase voltage constant, which will lead to the decrease of max electromagnetic torque 、 max start toque and overloading ability. And the mechanical characteristics of the induction motor can demonstrate as follows. The figure illustrates that it has mechanical characteristics in accord with the constant power control mode.

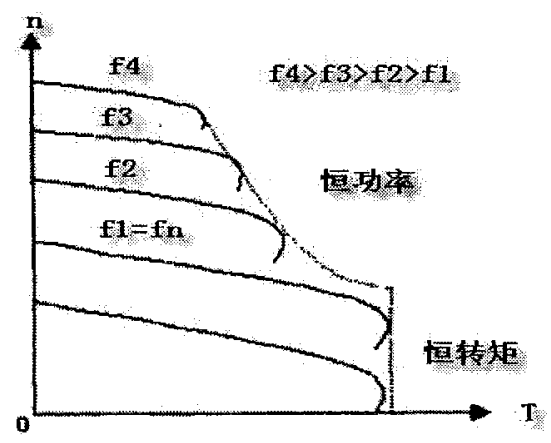

Figure 3. Constant power and constant torque mechanical characteristics.

So adopted inverter-driven technology, the induction motor not only provide better starting performance, adjustable speed, a wide speed range、 high efficiency, but also could run with constant power or torque control mode. Still the induction motor has a better performance such as: quick reflection, forward/reverse control, energy saving etc.[3]Constant torque control mode is recommended according to comprehensive analysis of the crimping machine.

\section{INVERTER-DRIVEN SYSTEM CONTROLLER RESEARCH}

\subsection{Operation flow chart of the crimping machine}

The system has three sensors, which transmit respective signal (accelerate、 decelerate、stop) to inverter. 

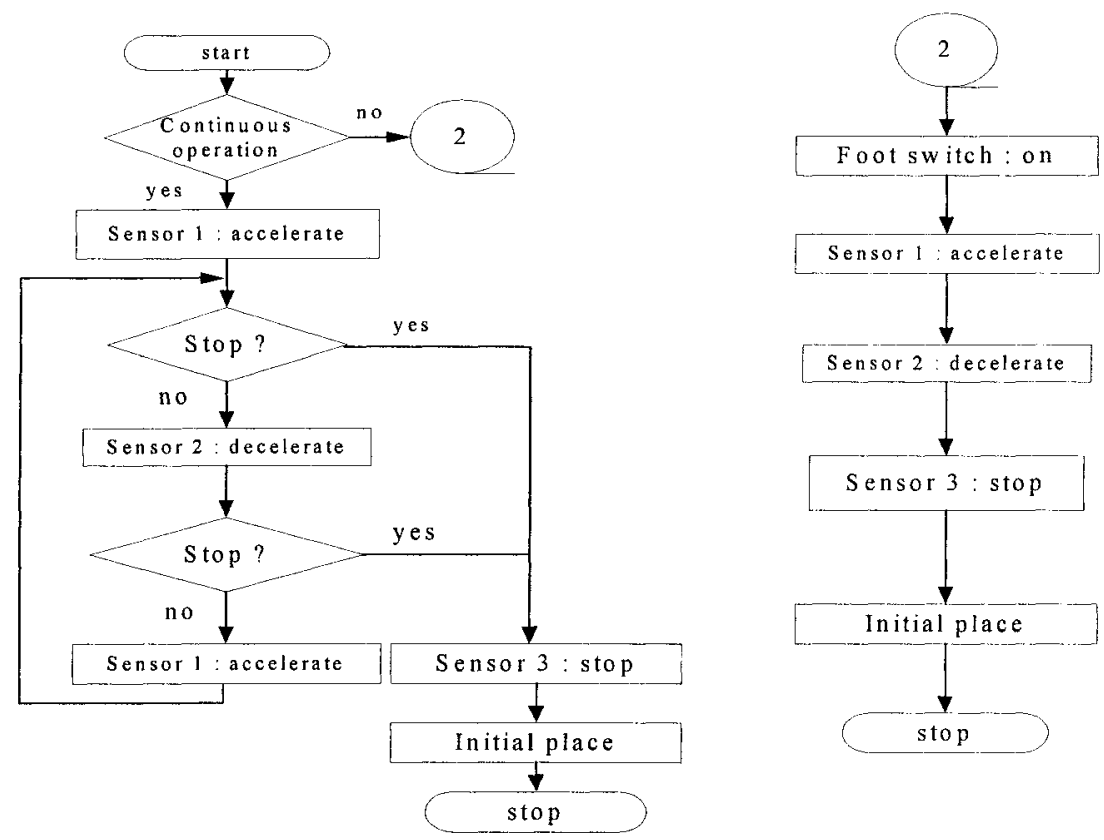

Figure 4. Operation flow chart of the crimping machine.

\subsection{Develop the inverter-driven system controller of the crimping machine}

Microprocessor is the core of the whole control system, how to choose a suitable one will have a crucial influence. Generally whether the microprocessor meets the requirement of the control system can be obtained by the following aspects: word length 、 instruction sorts and quantity 、 microprocessor speed、interrupt handling etc. The PSoC device includes programmable logic blocks and a processor core. They are userprogrammable devices, in which the designer can customize the configuration within development tools on their own computer. This microcontroller has digital and analog blocks (PSoC blocks) that can be configured into the desired peripherals. So all configurability can be handled through appropriate register settings that tell the specific PSoC block how to act, as well as controlling the traditional parameters such as input selection, compare values, and event actions etc. 


\subsubsection{The hardware module design of the controller}

1) The whole framework of the hardware system is as follows:

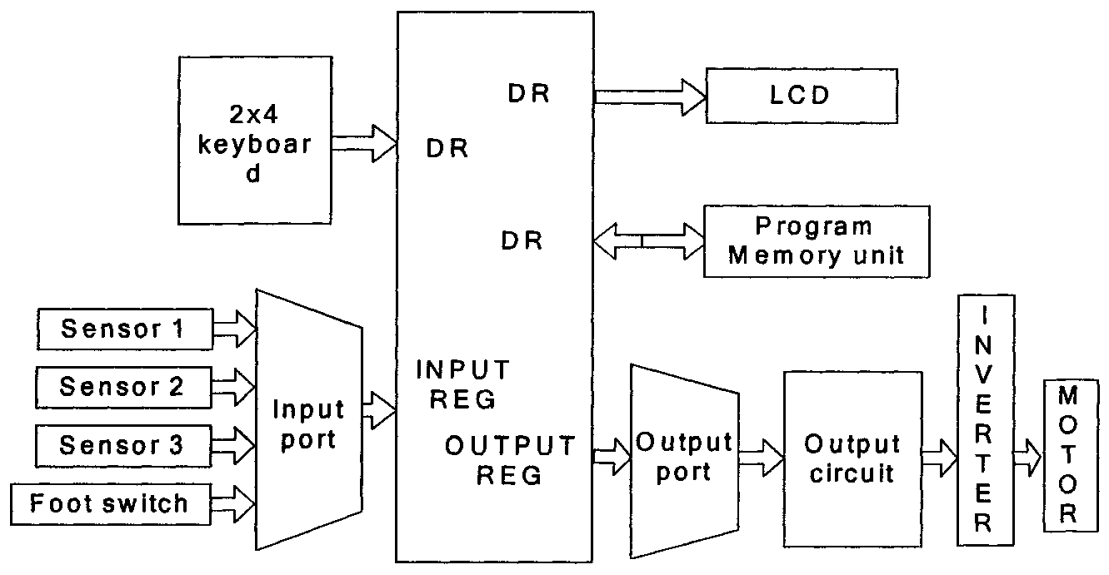

Figure 5. The framework of hardware system.

2) Inverter selection

Considering the requirement of quick start and efficient brake, as well as the high price versus performance ratio of the DELTA inverter, we take it into priority to drive the motor. The model of the motor is: YSJ8024,P=0.75KW, $\mathrm{I}_{\mathrm{n}}=3.48 \mathrm{~A}, \mathrm{n}=1440 \mathrm{r} / \mathrm{min}$. the output current of the inverter should in accord with the formula as follows:

$\mathrm{I}_{\mathrm{b}}>\mathrm{I}_{\mathrm{mn}}=\mathrm{KI}_{\mathrm{n}}=1.25 \mathrm{I}_{\mathrm{n}}=1.25 \times 3.48=4.35 \mathrm{~A}$

" $\mathrm{I}_{\mathrm{n}}$ " : rated current of the motor;

"Im": max operation current of the motor;

"K": overloading ability, 1.25 is recommended;

So the inverter parameters are as follows: $\mathrm{P}=0.75 \mathrm{KW}, \mathrm{I}_{\mathrm{b}}=11.5 \mathrm{~A}, \mathrm{P}_{\mathrm{CN}}$ $=1.9 \mathrm{KVA}$, model: VFD007M21A.

\subsubsection{The software design of the controller}

As we know the $C$ programming language is widely used now, it's easy to interface with system devices, as well as compact 、 convenient 、 expressive 、 flexible and powerful, so software system is developed with the $\mathrm{C}$ programming language. The customer could not only set the number 
and mode of the operation, but read the number counted on the liquid crystal display. The framework of the software is as follows:

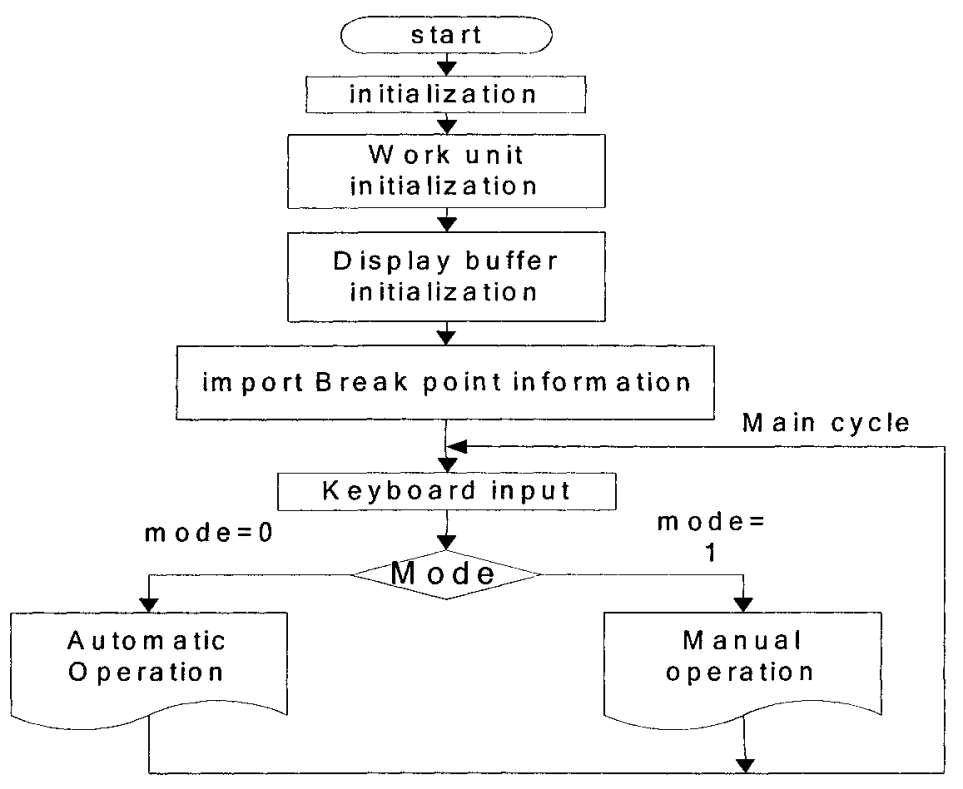

Figure 6. The framework of software design

\section{CONCLUSION}

Inverter technology is widely used for driving induction motors, in this paper the author has designed a new controller which allow the original crimping machine to abandon sophisticated mechanical device, reduce the mechanical impulsion, make the crimping machine noiseless, efficient and reliable. After innovative improvement, this machine must hit the market and obtain high economic returns for enterprises.

\section{REFERENCES}

[1]. Li Su. The direct torque control in asynchronous machine [M]. Beijing: China Machine Press, 2002.

[2] Bodson M, Chiasson J, Novotnak RT. A systematic approach to selecting optimal flux references in induction motors. IEEE Trans Control System Tech. 1999;3(4):388 - 97.

[3] Takahashi.I,Noguchi.T., A new quick-response and high efficiency control strategy of an induction motor. IEEE Trans.ind.appl.1999, P820 